\title{
Does Information Science Need History and Foundations?
}

\author{
Tim Gorichanaz \\ Drexel University \\ Philadelphia, USA \\ gorichanaz@drexel.edu
}

\author{
Elliott Hauser \\ University of North Carolina \\ Chapel Hill, USA \\ eah13@email.unc.edu
}

\author{
Yazdan Mansourian \\ Charles Sturt University \\ Wagga Wagga, Australia \\ ymansourian@csu.edu.au
}

\author{
Joseph T. Tennis \\ University of Washington \\ Seattle, USA \\ jtennis@uw.edu
}

\author{
Hilary Yerbury \\ University of Technology \\ Sydney, Australia \\ hilary.yerbury@uts.edu.au
}

\begin{abstract}
As ASIS\&T looks to the future, all community members are invited to contribute to a shared vision for information science. As a program of the SIG for History and Foundations (SIG-HFIS), this alternative event focuses on developing a vision for conceptual, philosophical, theoretical and historical work in information science. This event will provide a participatory platform to investigate questions such as: What is the domain of history and foundations? How does it relate to other research areas in the information field? The event will involve panelist interviews with diverse scholars, small-group discussions of big questions for history and foundations, and the presentation of a new idea-sharing platform, the HFIS Wishlist. This event will be a locus for participation and inspiration regarding historical and foundations work in information science as part of formulating a future vision for SIG-HFIS, ASIS\&T, and the information field more broadly.
\end{abstract}

\section{KEYWORDS}

Foundations research; philosophy of information; information science theory; information history.

\section{ASIS\&T THESAURUS}

Information science history; document theory.

\section{INTRODUCTION}

Information science is a dynamic field of study, shifting in its focus and interests over time as well as in its relation to other fields, all while remaining attentive to its goals of stewarding the cultural record (Furner, 2015). This year's conference themeanyone, anywhere, any time, any way - bears witness to that fact. As ASIS\&T looks to the future, President Elaine Toms shared a number of concepts that may inform a future vision of the Association-and, moreover, of information science as a field (personal communication, May 8, 2019). Several of these concepts involve empowering special interest groups (SIGs) in terms of reach and impact. We take this opportunity to invite members of the SIG for History and Foundations (SIG-HFIS), as well as other interested ASIS\&T members and conference attendees, to envision the role and future of historical and foundations work in information science.

SIG-HFIS exists to support and encourage historical and theoretical work in information science-including history, theories, fundamental concepts, and models (SIG HFIS, n.d.). Though SIG-HFIS is often styled "the history SIG," the SIG brings together a metatheoretically diverse group of ASIS\&T members-including philosophers, conceptual thinkers, empirical researchers and reflective practitioners, in addition to historians. And indeed, "history" was added to the group's name and remit in 1995, before which its explicit mandate was to explore the conceptual foundations of information science. The name change acknowledged the importance of the history of ideas and practice to theoretical work, but has also seeded some of the issues precipitating this event. As we look to the future, many questions arise:

- What is the connection between history and foundations?

- How do we define the domain of history and foundations?

- What is the relationship between this domain and others within information science?

- How can history and foundations work inform other fields of research and practice?

- How does SIG-HFIS connect with other SIGs?

- How can history and foundations work inspire others, both within and beyond information science? 
Such questions come up from time to time in the literature (e.g., Arafat \& Ashoori, 2019; Buckland, 2012). In the service of moving forward and inspiring further work, this alternative event will serve to encourage reflection and discussion on these and other questions. We will explore the work that the SIG has done while creating a vision for what a vibrant future for information science could be like. Specifically, the event will be comprised of three sections, in addition to a 5-minute welcome and 5-minute closing:

1. A panel of scholars at a range of career stages, whose work intersects with SIG-HFIS, share challenges and visions for history and foundations and ASIS\&T in talk-show-style interviews with a discussant. (20 minutes)

2. Participants form small groups to discuss three big questions, followed by a large-group summarization. (45 minutes)

3. HFIS Wishlist, a new tool for sparking creative thinking and sharing research ideas, is presented. (15 minutes)

After the event, outcome deliverables will be prepared and communicated. All these activities and outcomes are described in detail below.

\section{ABOUT THE PARTICIPANTS}

Tim Gorichanaz (Co-Organizer, Panelist)

Tim Gorichanaz is Assistant Teaching Professor at Drexel University, as well as chair-elect of SIG-HFIS. He works on document theory and information experience, which he explores in domains of personally meaningful activities, such as religious practice and hobbies. His paper "Document Phenomenology" (Gorichanaz \& Latham, 2016) was selected as Outstanding Paper in Journal of Documentation, and in 2017 he received the Litwin Books award for ongoing dissertation research in the philosophy of information.

Elliott Hauser (Co-Organizer, Discussant)

Elliott Hauser is a PhD candidate at the University of North Carolina School of Information and Library Science. His research examines the production of certainty in information systems.

\section{Yazdan Mansourian (Panelist)}

Yazdan Mansourian is a lecturer in the School of Information Studies at Charles Sturt University (CSU). He received his PhD in Information Science from the University of Sheffield. He has served as a faculty member, Director of the Central Library, and Head of LIS Department at Kharazmi University in Tehran. Yazdan joined CSU in 2017 and currently his main research interests are Human Information Behaviour, Information Seeking and Sharing in the Context of Serious Leisure, and Whole Person Approach in LIS. Yazdan is interested in the philosophical and theoretical aspects of LIS and various methods that we can use to put these theories into practice.

\section{Joseph T. Tennis (Panelist)}

Joseph T. Tennis is Associate Professor and Associate Dean for Faculty Affairs at the University of Washington Information School. His research centers on classification theory and is primarily concerned with examining how classification systems change over time, how diverse design requirements are invoked by different communities, and how these systems can interoperate in a web environment. He is increasingly interested in the ethics of information organization.

\section{Hilary Yerbury (Panelist)}

Hilary Yerbury is Adjunct Professor in Information Studies at University of Technology Sydney. She has a longstanding interest in the relationships between information and civil society. Her background in European social and political cultures and information management has influenced her concern for "thinking tools," conceptual frames, which can guide research and also inform practice. More recently, she has brought her interest in the use of information in everyday decision-making and in social change to the exploration of human rights activism and of the role of local NGOs from small nations at risk from climate change in knowledge creation and dissemination.

\section{OUTLINE OF THE SESSION}

\section{Welcome}

To kick off the session, Elliott Hauser and Tim Gorichanaz will welcome the attendees, describe the agenda for the event, and introduce the panelists. This section will last 5 minutes.

\section{Panelist Interviews}

In this section, scholars at a range of career stages will share their experiences, including challenges they faced entering the field, what ended up working, and their vision for the future of history and foundations and ASIS\&T. The purpose of this section is to elicit themes and background issues that will be taken up in the rest of the event. These will not be presentations, but rather brief, talk-show-style interviews led by Hauser as discussant. Each interview will last approximately five minutes, and as the conversation unfolds some questions may be directed at multiple panelists, and panelists may respond to each other. This section will last 20 minutes. 


\section{Discussion of Big Questions}

Next, participants will form small groups of 6-8 people each to discuss three big questions, with a scribe designated to record the discussion. Each question will be discussed simultaneously for 5 minutes, timed and facilitated by Gorichanaz. After each question, groups will report back for a 10-minute whole-room discussion. Common findings and summaries of the discussions will be recorded by Hauser. The three big questions are:

1. In your view, what is the role of history and foundations work in information science?

2. What particular historical or conceptual works had a major influence on your own research or practice, and how?

3. What are the key outlets for this kind of work, and what impact do they have? (Publication venues, conferences, etc.)

Notes and other records will be then collected by Gorichanaz. This section will last 45 minutes.

\section{Sparking Further Research: HFIS Wishlist}

In this final section of the event, Gorichanaz and Hauser will introduce HFIS Wishlist, a tool for sparking creative thinking. The purpose of this section of the event is to catalyze participation in history and foundations work beyond this event, as well as spark creative thinking in research. It is expected that some will have a burning idea, while others will be interested in hearing and responding to what others have to say; HFIS Wishlist will appeal to both groups.

HFIS Wishlist is inspired by the Manuscript Wishlist movement (MSWL, see https://manuscriptwishlist.com) in the publishing industry. In MSWL, literary agents and editors post wishlists for works that they would consider representing or publishingin short, things they'd like to see in the world-e.g., "a young-adult paranormal legal thriller." HFIS Wishlist will show a stream of submissions in the form: "I want to read a paper that..." (see Figure 1). Authors could elaborate, for instance describing why they are interested, how they would cite this work, etc. The HFIS Wishlist system is currently in development by Gorichanaz and Hauser, and it will be complete in Summer 2019. Prior to the conference, Gorichanaz and Hauser will publicize the system on the SIG-HFIS Community and other communications platforms with a handful of seeded examples (e.g., "I want to read a paper that proposes a field of critical bibliometrics") and invite others to submit their own examples. These may be ideas that the author hopes to pursue one day themselves, giving the chance to get feedback on the concept, or ideas that they would invite others to pursue.

It should be noted that HFIS Wishlist is only a beginning: The goal with the system will be to expand it to other research areas within information science, encouraging cross-, trans-, inter- and multidisciplinary thinking.

In this stage, Gorichanaz and Hauser will verbally present HFIS Wishlist and lead a discussion around the possibilities of the platform and in the research-domain specifics of some of the proposals therein. Considerations may include: How would I react to this as a potential reader/reviewer? Does this make me excited? How does this build on what we've discussed so far? I had a paper like this rejected—what am I doing wrong? This section will last 15 minutes.

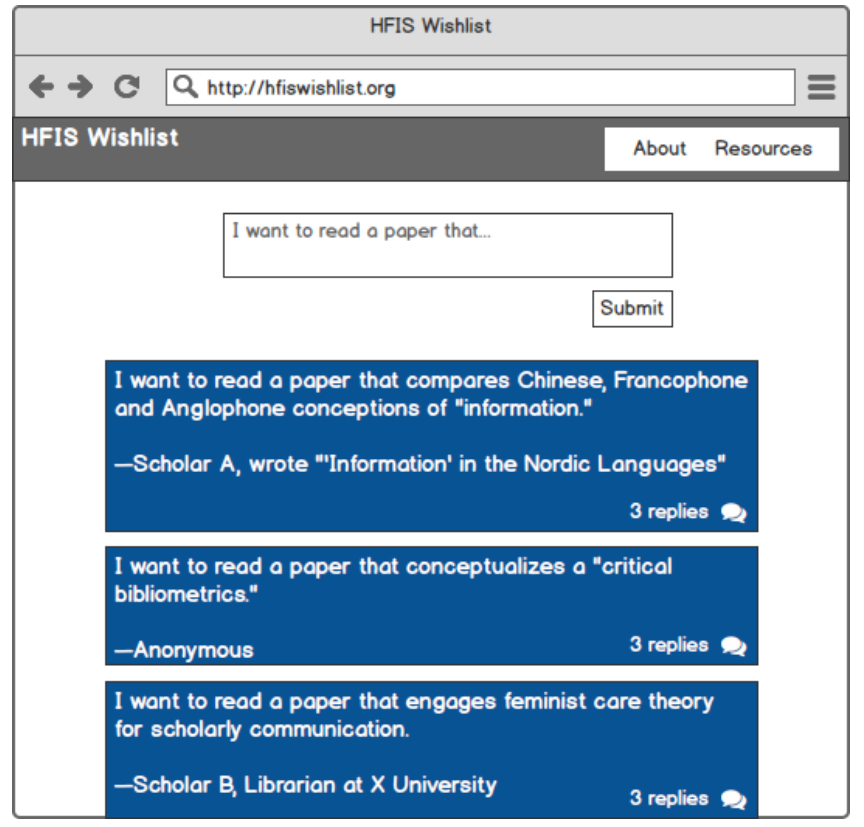

Figure 1. Mockup of HFIS Wishlist system 


\section{Closing}

In this final section of the event, major points will be summarized, and the outcomes (see below) will be explained. Participants will be invited to join SIG-HFIS. This section will last 5 minutes.

\section{OUTCOMES OF THE EVENT}

We expect that the event will inspire interest in history and foundations research, and perhaps spark some concrete ideas. Beyond this, we envision three immediate, concrete outcomes:

1. A white paper summarizing the session, functioning as a manifesto for future history and foundations work, to be published on the SIG-HFIS website and shared in the SIG-HFIS newsletter and other venues.

2. Updates to the SIG-HFIS website, including, e.g., a link to HFIS Wishlist, a list of the inspiring history and foundations works and publication outlets mentioned in the Discussion of Questions.

3. The development of The Foundry, a virtual working group on history and foundations work, to meet on an ongoing basis and discuss in-progress work in this domain, to be led by Hauser.

These outcomes will be communicated first and chiefly through the ASIS\&T Community platform of SIG-HFIS, but the organizers will seek out other opportunities to bring these conversations to wider audiences.

\section{CONCLUSION}

This alternative event will be a locus for participation and inspiration regarding the role of historical and foundations work in information science. We hope to envision and model the future of SIG-HFIS, ASIS\&T, and the field of information science more broadly by deeply engaging with our participant and panelist colleagues on these important issues.

\section{REFERENCES}

Arafat, S., \& Ashoori, E. (2019). Search foundations: Toward a science of technology-mediated experience (History and foundations of information science). Cambridge, MA: The MIT Press.

Buckland, M. K. (2012). What kind of science can information science be? Journal of the American Society for Information Science, 63(1), 1-7.

Furner, J. (2015). Information science is neither. Library Trends, 63(3), 362-377.

Gorichanaz, T., \& Latham, K. F. (2016). Document phenomenology: A framework for holistic analysis. Journal of Documentation, 72(6), 1114-1133.

SIG HFIS. (n.d.). ASIS\&T SIG HFIS : History \& Foundations of Information Science. Retrieved from https:/www.asist.org/SIG/SIGHFIS/ 